\title{
Cervical Radiculopathy Focus on Characteristics and Differential Diagnosis
}

\author{
Kyung-Chung Kang, Hee Sung Lee, Jung-Hee Lee \\ Department of Orthopedic Surgery, Kyung Hee University Hospital, Kyung Hee University School of Medicine, Seoul, Korea
}

Cervical radiculopathy is characterized by neurological dysfunction caused by compression and inflammation of the spinal nerves or nerve roots of the cervical spine. It mainly presents with neck and arm pain, sensory loss, motor dysfunction, and reflex changes according to the dermatomal distribution. The most common causes of cervical radiculopathy are cervical disc herniation and cervical spondylosis. It is important to find the exact symptomatic segment and distinguish between conditions that may mimic certain cervical radicular compression syndromes through meticulous physical examinations and precise reading of radiographs. Non-surgical treatments are recommended as an initial management. Surgery is applicable to patients with intractable or persistent pain despite sufficient conservative management or with severe or progressive neurological deficits. Cervical radiculopathy is treated surgically by anterior and/or posterior approaches. The appropriate choice of surgical treatment should be individualized, considering the patient's main pathophysiology, specific clinical symptoms and radiographic findings thoroughly.

Keywords: Cervical radiculopathy; Characteristics; Differential diagnosis

\section{Introduction}

Cervical radiculopathy is characterized by neurological dysfunction caused by compression and inflammation of the spinal nerves or nerve roots of the cervical spine. The incidence and prevalence rate of cervical radiculopathy are unclear, and epidemiological data are limited. In a large-scale retrospective population-based study, the incidence rate was 83.2 per 100,000 people (107.3 men and 63.5 women), with the peak incidence in the fifth decade [1]. A recent US military study found an incidence of 1.79 per 1,000 person-years [2].

Depending on the segments involved and severity of neurological dysfunction, various signs and symptoms of cervical radiculopathy may manifest as neck and uni- lateral arm pain with numbness, weakness, or altered reflexes [3]. It is important to find the exact symptomatic segment and distinguish between conditions that may mimic certain cervical radicular compression syndromes through various provocation physical examinations and radiographs. Conservative or surgical treatments may be considered to reduce pain, improve neurological function, prevent recurrence, and allow the patient to return to daily life. In this review article, we address the pathophysiology, characteristics, differential diagnosis, and treatment options for cervical radiculopathy.

\section{Pathophysiology}

Cervical radiculopathy is the pathological process associ-

Received Dec 14, 2020; Accepted Dec 14, 2020

Corresponding author: Kyung-Chung Kang

Department of Orthopedic Surgery, Kyung Hee University Hospital, 23 Kyungheedae-ro, Dongdaemun-gu, Seoul 02447, Korea

Tel: +82-2-958-8346, Fax: +82-2-964-3865, E-mail: futurespine@gmail.com 
ated with the cervical spinal nerve or nerve root compression and inflammation. The most common causes of cervical radiculopathy are cervical disc herniation and cervical spondylosis.

Disc herniation is more commonly associated with lumbar radiculopathy than with cervical radiculopathy. Disc herniation is responsible for only $21.9 \%$ of cervical radiculopathy cases [1]. Cervical spondylosis refers to degenerative changes that result from aging in most adult populations. Disc degeneration with age leads to decreased disc height and foraminal narrowing. Decreased disc height causes the increased loads to the vertebral body and the intervertebral joints of Luschka (uncovertebral joints). This leads to osteophyte formation and bony hypertrophy. Hypertrophy of the uncovertebral and facet joints can cause foraminal stenosis and cervical radiculopathy $[4,5]$.

Cervical radiculopathy is less commonly caused by tumors, trauma, synovial cysts, meningeal cysts, dural arteriovenous fistulae [6], or tortuous vertebral arteries [7]. It mainly presents with neck and arm pain, sensory loss, motor dysfunction, and reflex changes according to the dermatomal distribution.

\section{Characteristics}

\section{Clinical diagnosis}

There are no universally accepted criteria for diagnosing of cervical radiculopathy. Generally, cervical radiculopathy patients have various signs and symptoms, such as neck and unilateral arm pain with numbness, weakness, or altered reflexes [3]. The main signs and symptoms of patients are arm pain in $97 \%-99 \%$, sensory deficit in $85 \%-91 \%$, reflex deficit in $71 \%-84 \%$, neck pain in $56 \%$ $80 \%$, motor deficit in $64 \%-70 \%$, scapular pain in $37 \%-$ $52 \%$, anterior chest pain in $18 \%$, and headaches in $10 \%$ (Table 1) [8-10]. The clinical diagnosis can be made based on the patient's medical history and physical examination [11]. The diagnosis is then verified by radiographs or supported by surgical results [12].

There are several provocative tests to evaluate cervical radiculopathy, but only a few of them have reliably yielded statistically significant differences between patients and controls in research setting. The Spurling test has been demonstrated to have low to moderate sensitivity (30\%$50 \%)$ and moderate to high specificity $(74 \%-93 \%)$, neck
Table 1. Clinical symptoms and proportions of cervical radiculopathy

\begin{tabular}{lc|}
\hline Symptom & Proportion (\%) \\
\hline Arm pain & $97-99$ \\
\hline Sensory deficit & $85-91$ \\
\hline Reflex deficit & $71-84$ \\
\hline Neck pain & $56-80$ \\
\hline Motor deficit & $64-70$ \\
\hline Periscapular pain & $37-52$ \\
\hline Anterior chest pain & 18 \\
\hline Headaches & 10 \\
\hline
\end{tabular}

Table 2. Sensitivity and specificity of conventional provocative tests in cervical radiculopathy

\begin{tabular}{lcc} 
Variable & Sensitivity $(\%)$ & Specificity $(\%)$ \\
\hline Spurling & $30-50$ & $74-93$ \\
Shoulder abduction & $17-78$ & $75-92$ \\
\hline Valsalva & 22 & 94 \\
\hline Distraction & 44 & $90-97$ \\
\hline Upper limb tension test & $72-97$ & $11-33$ \\
\hline
\end{tabular}

traction test showed moderate sensitivity (44\%) and high specificity (90\%-97\%), and Valsalva's maneuver showed low sensitivity (22\%) and high specificity (94\%). The upper limb tension test had high sensitivity $(72 \%-97 \%)$ and low specificity (11\%-33\%), while the shoulder abduction test had low to moderate sensitivity $(17 \%-78 \%)$ and moderate to high specificity (75\%-92\%) (Table 2) [13-17]. Positive results for two or more simultaneous provocation tests are considered to increase the accuracy of the diagnosis of cervical radiculopathy.

\section{Imaging studies}

Conventional radiographs are commonly obtained to evaluate cervical lesions, including fractures, tumors, degenerative pathologies, etc. Although their usefulness is limited due to low diagnostic sensitivity, conventional radiographs are considered as an important screening tool. In particular, oblique views of the cervical spine are used to assess the patency of the intervertebral foramina [18]. They are inexpensive, reproducible, and facilitatory in evaluating fractures, instability, and deformity.

Computed tomography (CT) helps assess pathologies that cause neural compression, such as bony spurs, fo- 

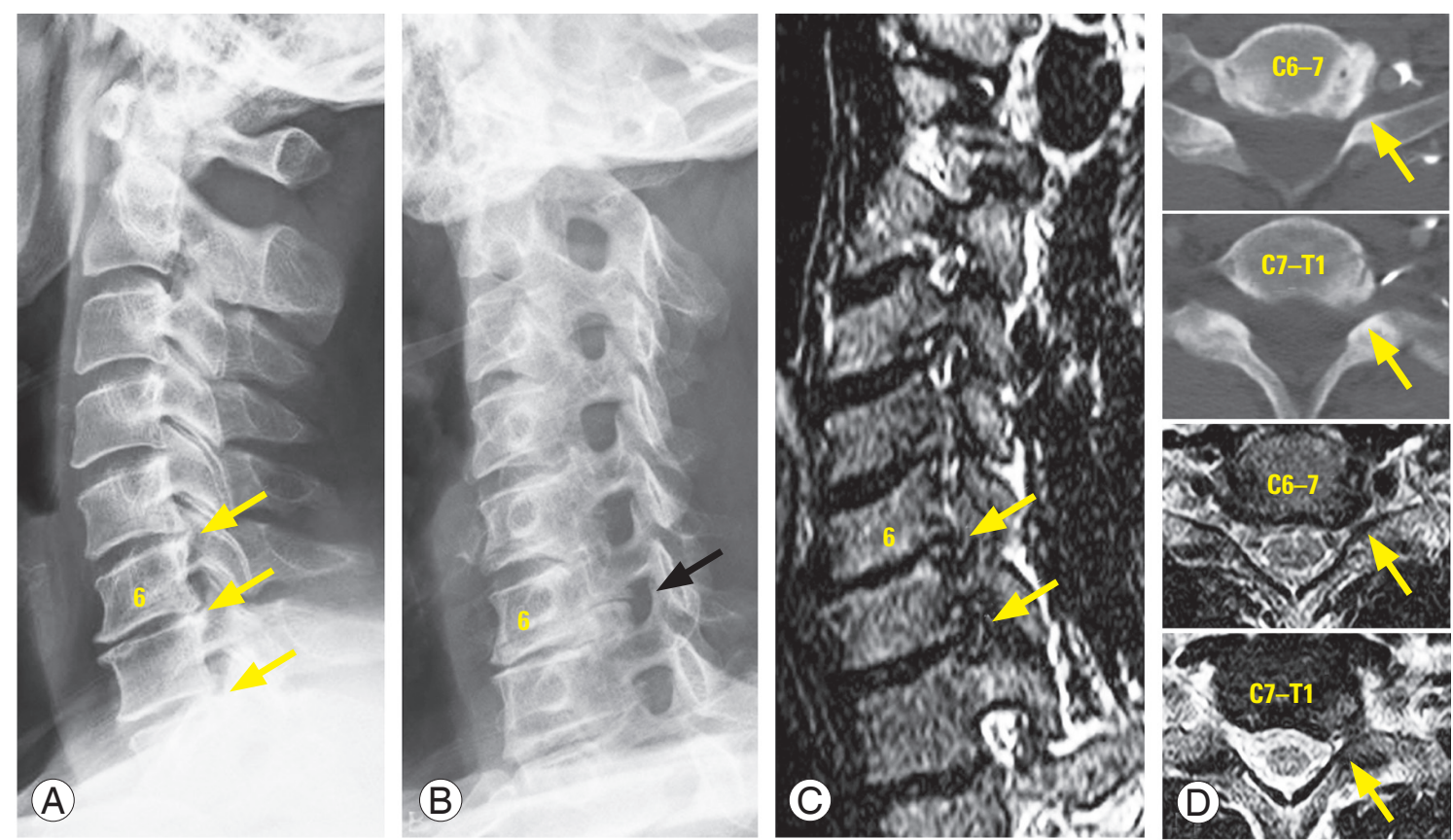

Fig. 1. A 53-year-old male patient's radiographs of cervical spine. He complained severe left-side scapular medial border pain and weakness of left finger extension. Intervertebral disc space narrowing and posterior ostephytes were observed in multiple levels (A, yellow arrows) and large bony spur and foraminal stenosis were well presented at C6-7 segment of oblique X-ray (B, black arrow). The C6-7 and C7-T1 foraminal stenoses seems to be more clear in oblique coronal images of magnetic resonance imaging (C) than in axial computed tomography scans or magnetic resonance images (D).

raminal stenosis, facet hypertrophy, and ossification of the posterior longitudinal ligament. The diagnostic accuracy of CT has been shown to be moderate to high $(72 \%-91 \%)$ [19]. CT myelography is an invasive study that may be more effective in distinguishing soft tissue from bony pathology. When combined with myelography (CT myelography), the accuracy has been reported to increase to $96 \%$ [20-23].

Magnetic resonance imaging (MRI) is the most common imaging method for detecting cervical spine pathologies because it can detect cervical neural lesions directly and non-invasively [24]. Brown et al. [25] reported that MRI predicted $88 \%$ of cervical lesions. MRI can be combined with CT or CT myelography to improve diagnostic accuracy. Recently, the importance of oblique MRI views of in the cervical spine has been increasingly emphasized for the assessment of foraminal stenosis [26,27] (Fig. 1).

\section{Electrodiagnostic studies}

Electrodiagnostic studies are useful for distinguishing cervical radiculopathy from other lesions that are not clear on physical examination. Electromyography (EMG) analyzes multiple muscles within the same myotome and in adjacent myotomes. Nerve conduction studies (NCS) are conducted to exclude peripheral neuropathy and measure amplitude, distal latency, and conduction velocity.

Abnormal findings, including positive sharp waves and fibrillation potentials, may not occur within 3 weeks of the onset of nerve compression [28]. EMG results may not be abnormal in the presence of mild radiculopathy or primarily sensory radiculopathy, and they are likely to be benign in patients without pronounced weakness. The efficacy of EMG as a tool to diagnose cervical radiculopathy accurately is estimated to be $57 \%$ to $90 \%$ [29-33]. Nardin et al. [31] retrospectively studied 47 patients with cervical and lumbar radiculopathy who were assessed by both EMG and spine MRI studies. They found that 55\% of patients had EMG abnormalities and 57\% had MRI abnormalities related to the clinically estimated level of radiculopathy. The modalities were concordant for the majority (60\%) of patients, with findings of both normal for 11 and both abnormal for 17. However, the modalities were discordant in a significant minority (40\%), suggesting that both EMG and MRI remain complementary diagnostic tools [31]. Therefore, EMG and NCS should be considered as supportive tools for a more accurate diagnosis of cervical radiculopathy and should not be considered definitive on their own. 


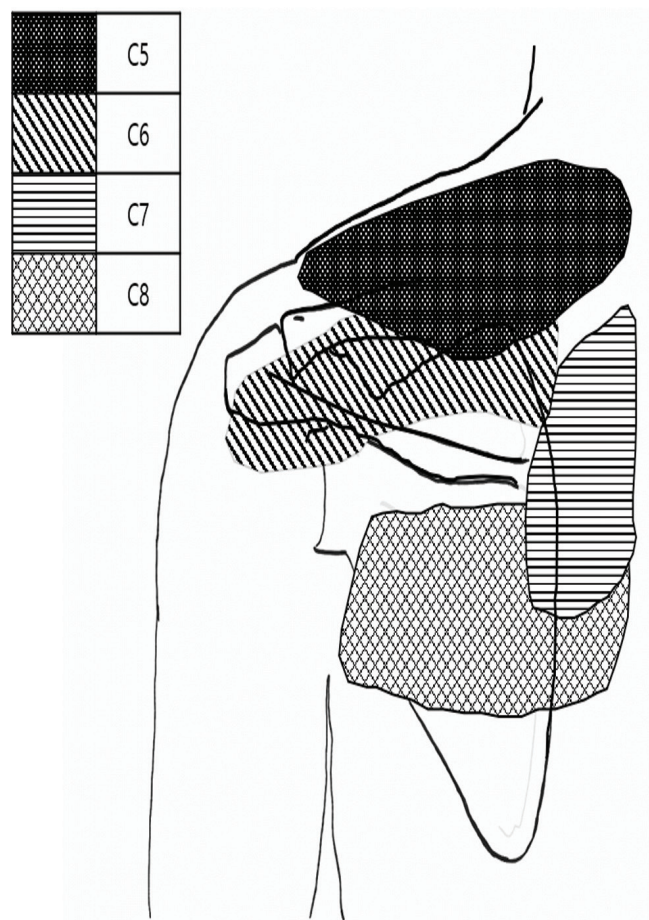

Fig. 2. Differential diagnosis of peri-scapular pain in according to the dermatomal distribution of lower cervical spinal nerves. Pain on supra-scapular areas are associated with $\mathrm{C} 5$ or $\mathrm{C6}$ radiculopathies, interscapular and infra-scapular pains are considered to be mainly from $\mathrm{C} 7$ and $\mathrm{C} 8$ radiculpathy, respectively.

\section{Differential Diagnosis}

The expression of the patient's symptoms is determined by the level at which the cervical nerve root is compressed. According to the previous literatures, peri-scapular pain also showed dermatomal distributions of lower cervical spinal nerves [34,35] (Fig. 2). It is important to distinguish between conditions that may mimic certain cervical radicular compression syndromes.

C2-4 radiculopathy is not common. Patients often complain of occipital or temporal pain that extends to the back of the ear or side of the neck. This is difficult to distinguish from other causes of headache such as migraine [36]. Motor deficits generally may be hard to detect. The C3 and C4 nerve roots innervate the diaphragm, and these cervical radiculopathies can lead to diaphragmatic weakness and a pattern of breathing referred to as paradoxical respiration [37,38].

C5 radiculopathy leads to symptoms similar to that of a rotator cuff tear. While both can cause weakened shoulder abduction, C5 radiculopathy is not associated with shoulder pain during passive exercise or tenderness.
Carpal tunnel syndrome (CTS) mimics C6 radiculopathy. A patient with $\mathrm{C} 6$ radiculopathy usually feels pain or numbness from the neck to radial side of the biceps, forearm, the dorsal web space of the hand between the thumb and index finger, and to the tips of those fingers. However, CTS usually involves the radial three and a half digits and is manifested by thenar muscle atrophy. Tinel's sign, Phalen's maneuver, or Durkan's test may be positive in patients with the CTS. Motor deficits of the wrist extensors and biceps are common in association with C6 radiculopathy. The brachioradialis and biceps reflexes may be changed.

The C7 nerve root is the most frequently involved by cervical radiculopathy. Entrapment of the posterior interosseous nerve may be mistaken for the motor component of the $\mathrm{C} 7$ radiculopathy causing weakness of triceps, wrist flexors and finger extensors. However, sensory changes are absent, and the triceps and wrist flexors have normal strength in posterior interosseous neuropathy. Usually, when patients explain their symptoms, patients with C6 radiculopathy or CTS show the volar side of their hands, but patients with $\mathrm{C} 7$ radiculopathy often express symptoms by pronating the forearms.

Additionally, ulnar entrapment at the level of the elbow (cubital tunnel syndrome) can cause clinical tenderness along the medial side of the elbow and hypothenar muscles, as well as adductor pollicis weakness, sensory changes in the hand and fourth and fifth fingers. Patients with C8 radiculopathy complain of profound weakness of the intrinsic hand muscles and difficulty using their hands in daily life [4,39-42] (Table 3).

\section{Natural History}

Lee and Turner reported that the natural history of cervical radiculopathy was generally favorable and self-limited. In mid- to long-term follow-up (2 to 19 years) of $51 \mathrm{pa}$ tients with radiculopathy, $43.1 \%$ had no symptoms, $29.4 \%$ had mild or intermittent symptoms, and only $27.5 \%$ had persistent or worsening symptoms. Progressive neurologic deficits or myelopathic symptoms did not develop in any of radiculopathy patients at follow-up [43]. Significant improvement in pain and disability tends to occur within 4 to 6 months after onset. Eighty-three percent of patients took 2 to 3 years to fully recover and $22 \%$ had moderate pain recurrence 2 to 3 years, but not as severe as the initial pain onset $[44,45]$. Since the natural history of cervical 


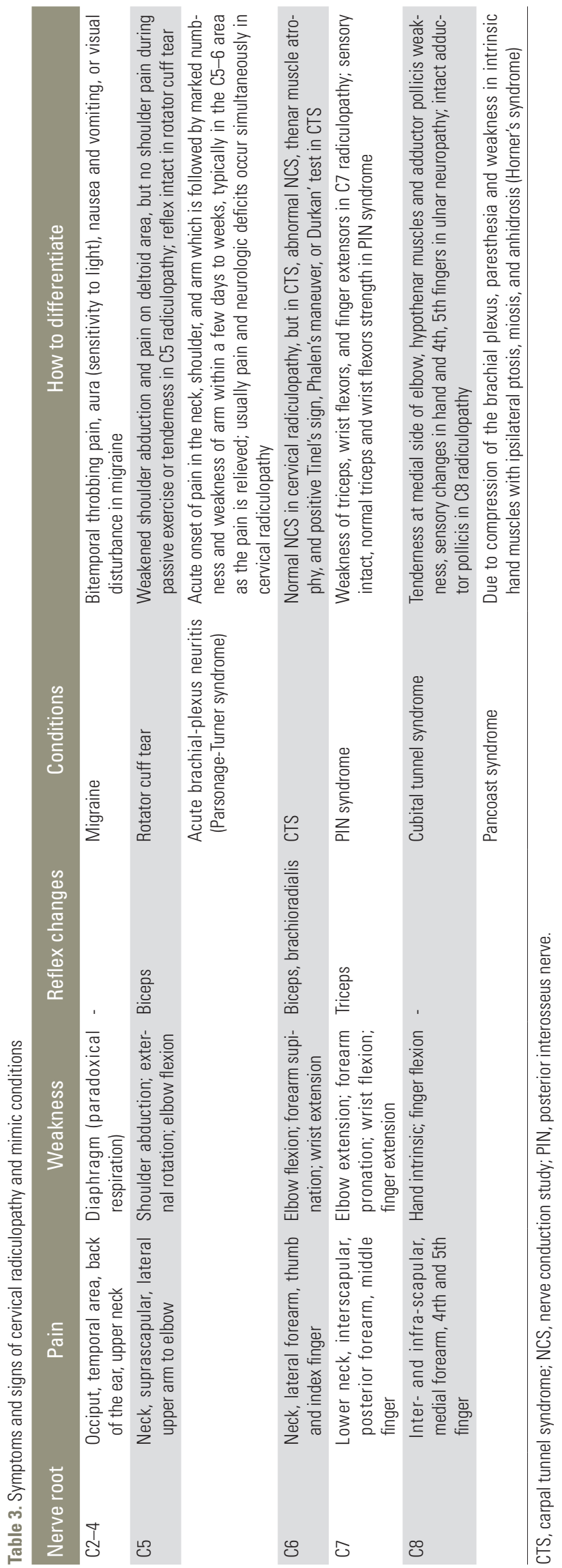

radiculopathy often appears to be favorable in spite of soft disc herniation or osteophyte [46], conservative treatment is considered as the initial treatment of choice for most cases without progressive neurologic deficit or debilitating pain.

\section{Treatment Options}

\section{Conservative treatment}

The goals of treatment are to reduce pain, improve neurological function, prevent recurrences, and allow the patient to return to daily life. Initially, non-surgical treatments, such as immobilization (cervical collar), traction, massage, oral medication, physical therapy, cervical manipulation, and cervical steroid injection, are recommended. In the literatures, high-quality evidences for the effectiveness of these conservative treatments are lacking, and these are considered for symptomatic relief only [9]. There have been no randomized controlled trials (RCTs) supporting the use of immobilization, traction, and massage for patients with cervical radiculopathy, and oral medication use is also supported by limited evidence, except for the short-term use of oral corticosteroids [47]. Meanwhile, some cohort studies and RCTs have demonstrated significant benefits yielded by supervised and home-based physical therapy [48-50], but the efficacy of cervical manipulation for radiculopathy is not supported by sufficient evidence.

Cervical steroid injections can be considered for patients who do not respond to 4 to 6 weeks of other conservative management options. There is high-quality evidence supporting the use of cervical steroid injections for cervical radiculopathy caused by disc herniation, but fair evidence for spondylosis [51]. Although such injections are considered to be relatively safe, there are concerns about complications, such as dural puncture, epidural hematoma, nerve root injury, or cord infarction $[46,52,53]$.

\section{Surgical treatment}

Surgery is applicable to patients with intractable or persistent pain despite sufficient conservative management for at least 6 to 12 weeks or to patients with severe or progressive neurological deficits. Cervical radiculopathy is treated surgically by anterior or posterior approaches [54]. For patients with cervical kyphosis [55], anterior procedures 

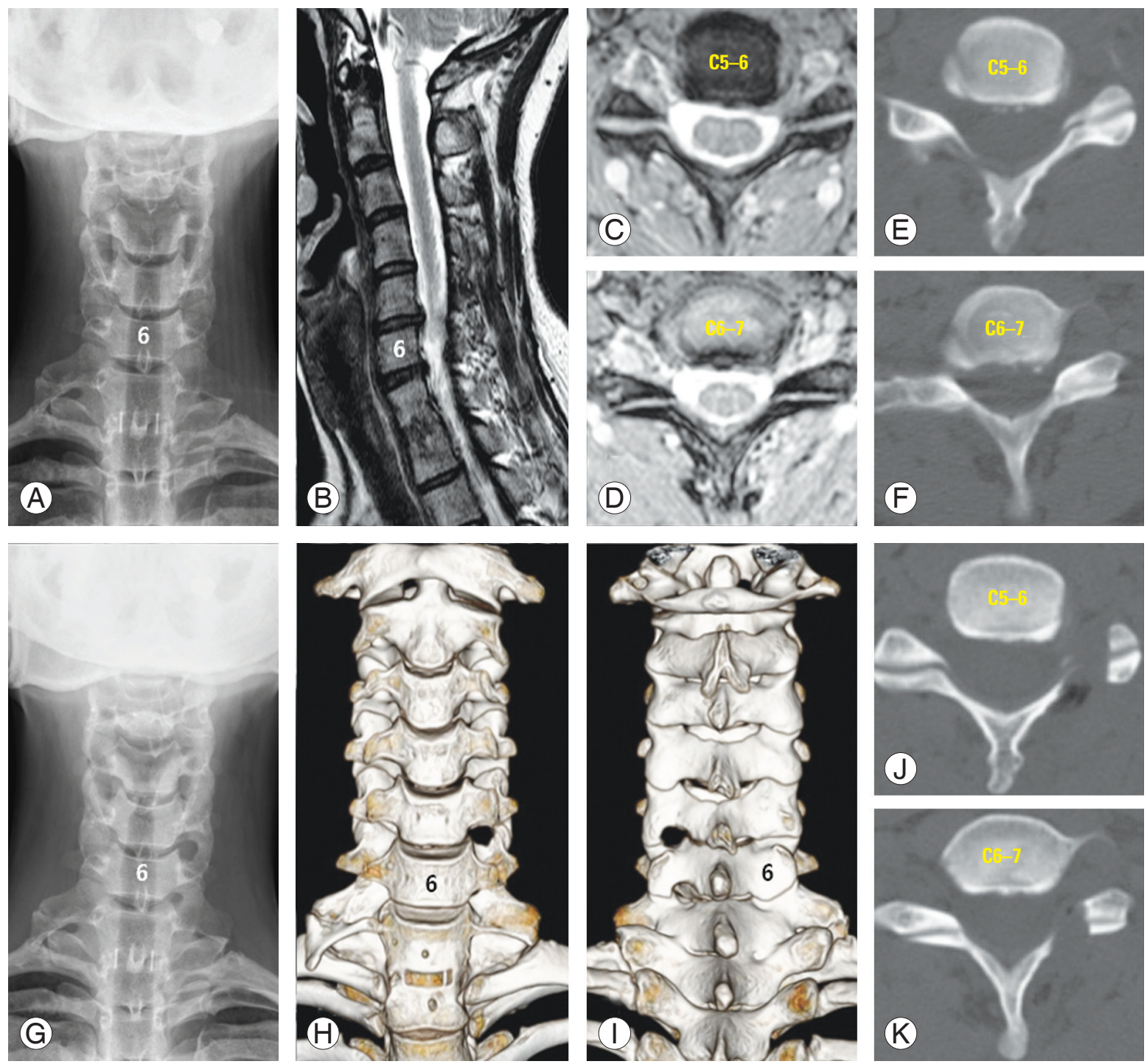

Fig. 3. A 43-year-old right hand dominant female with a previous history of C7-T1 anterior cervical discectomy and fusion presented with significant pain on posterior neck, left side of supra-scapular area, radial side arm and 1st \& 2nd fingers. (A) Plain radiograph of cervical spine showed the prior C7-T1 fusion. Magnetic resonance imaging (B) and CT revealed disc protrusion and foraminal stenosis at the left-side of C5-6 (C, E) and C6-7 (D, F) segments. The patient underwent left C5-6 and C6-7 PCF. The postoperative plain radiograph (G) and CT (H, I) showed the left-side PCF state on C5-6 (J) and C6-7 (K). After surgery, her radicular symptom was completely resolved. CT, computed tomography; PCF, posterior cervical foraminotomy.

Table 4. Surgical approaches for cervical radiculopathy

\begin{tabular}{|c|c|c|c|}
\hline Approach & Advantages & Disadvantages & Critical content in literatures \\
\hline ACDF & $\begin{array}{l}\text { Direct removal of anterior pathology; bone graft or cages; } \\
\text { maintain cervical disc height and prevent kyphosis }\end{array}$ & Pseudarthrosis; hardware failure; ASD & $25 \%$ of $A S D$ in 10 years \\
\hline CDA & $\begin{array}{l}\text { Motion preservation; avoidance of non-union; prevention of } \\
\text { adjacent segmental degeneration }\end{array}$ & $\begin{array}{l}\text { Ectopic ossification; progressive decrease of } \\
\text { neck motion; no long-term follow-up }\end{array}$ & FDA approved for single- and two-level \\
\hline PCF & $\begin{array}{l}\text { Minimal invasiveness; avoidance of fusion; preservation of } \\
\text { neck motion and ASD; cost effectiveness }\end{array}$ & $\begin{array}{l}\text { Incomplete decompression; deterioration of } \\
\text { pathology at index level; facet violation }\end{array}$ & $\begin{array}{l}\text { Improvement in about } 90 \% \text { of patients } \\
\text { within a mean follow-up of } 10 \text { years }\end{array}$ \\
\hline
\end{tabular}

ACDF, anterior cervical discectomy and fusion; ASD, adjacent segmental disease; CDA, cervical disc arthroplasty; FDA, U.S. Food and Drug Administration; PCF, posterior cervical foraminotomy. 
including cervical discectomy, corpectomy and cervical disc arthroplasty (CDA) are generally preferred by using bones, cages, and plates.

\section{1) Anterior cervical discectomy and fusion}

Anterior cervical discectomy and fusion (ACDF) is the most commonly performed procedure for cervical radiculopathy. It involves removing all disc material anteriorly from the uncinate process to adjacent uncinate process following placement of bone grafts or cages to maintain cervical disc height and prevent kyphosis resulting in indirect foraminal decompression. As a result, $87.8 \%$ of the patients were functionally and neurologically satisfied with results following ACDF. However, ACDF is known to be associated with complications, such as dysphagia, hoarseness, airway obstruction, hardware failure, nonunion, and adjacent segmental degeneration (ASD). Hilibrand and Robbins [56] described ASD as radiographic degeneration at the level adjacent to the previous fusion leading to new neurological sequelae. The expected incidence of new symptomatic adjacent-level disease increases by about $2.9 \%$ annually after fusion and is $25.6 \%$ at postoperative 10 years [57], but it is unclear whether ASD reflects the natural history of cervical spondylosis or is the consequence of cervical spinal fusion. Despite the risk of complications, ACDF is still considered the "gold standard" for cervical radiculopathy treatment in 1, 2, or 3 levels.

\section{2) Cervical disc arthroplasty}

$\mathrm{CDA}$ is performed through an approach similar to that of ACDF, but a prosthesis is placed in the decompressed disc space instead of graft materials. The advantages of $\mathrm{CDA}$ include the avoidance of nonunion and the prevention of ASD by motion preservation. Since the advent of $\mathrm{CDA}$, many studies have shown that there is not much difference between the ACDF and CDA groups in terms of outcomes [58,59]. However, more recently, CDA was formally approved by the U.S. Food and Drug Administration for single- and two-level cervical degenerative disc disease [60]. Several reviews have concluded that CDA is superior to $\mathrm{ACDF}$ in long-term clinical success rates and better functional outcome measurements [61,62]. Until now, some controversial issues still remain unresolved, including surgical outcomes, ASD, heterotopic ossification, wear debris, and multi-level CDA. It is too early to draw definitive conclusions about the efficacy and costeffectiveness of CDA; such clarity will require further well-designed research and considerable time [63].

\section{3) Posterior cervical foraminotomy}

If the cervical lordosis is preserved without spinal cord compression, posterior cervical foraminotomy (PCF) can be considered for cervical radiculopathy. Since the 1940s, when the PCF was introduced, development of the technique has been remarkable, particularly in recent years. PCF has the advantages of avoiding fusion, preserving motion and preventing of ASD [64,65]. The main issues associated with complication after PCF are symptom recurrence at the surgical segment due to incomplete decompression, degeneration of the index level, and nerve root injury. In the literatures, the surgical outcomes of PCF generally reported as favorable. With a mean followup of 10 years, Church et al. [66] reported satisfactory surgical results in approximately $90 \%$ of their study patients, and $93 \%$ of patients were able to return to work. The recurrence of radiculopathy requiring reoperation was only $6.2 \%$ and the overall complication rate in this study was only $3.3 \%$ [66]. In terms of pain improvement, complications, and quality of life, short- and long-term postoperative outcomes of PCF are almost similar to those of ACDF $[67,68]$. For the appropriate indications, PCF is considered an important treatment with considerable merits, particularly for patients with multi-level radiculopathy or previous anterior operations $[8,69,70]$ (Fig. 3, Table 4).

\section{Conclusions}

Cervical radiculopathy often causes neck and arm pain as a result of disc herniation or cervical spondylosis. Thorough medical history taking and physical examination, along with radiographic and electrodiagnostic studies can help identify pathologies and exclude other causes of upper limb dysfunction. Cervical radiculopathy is initially treated conservatively. When the patient suffers from intractable pain or progressive neurology, operative treatment can be considered. Either anterior or posterior approaches should be determined under appropriate circumstances, understanding that each technique has its own advantages and disadvantages.

\section{Conflict of Interest}

No potential conflict of interest relevant to this article was reported. 


\section{References}

1. Radhakrishnan K, Litchy WJ, O’Fallon WM, Kurland LT. Epidemiology of cervical radiculopathy: a population-based study from Rochester, Minnesota, 1976 through 1990. Brain 1994;117:325-35.

2. Schoenfeld AJ, George AA, Bader JO, Caram PM Jr. Incidence and epidemiology of cervical radiculopathy in the United States military: 2000 to 2009. J Spinal Disord Tech 2012;25:17-22.

3. Bogduk N. The anatomy and pathophysiology of neck pain. Phys Med Rehabil Clin N Am 2003;14:455-72.

4. Ahlgren BD, Garfin SR. Cervical radiculopathy. Orthop Clin North Am 1996;27:253-63.

5. Hartman J. Anatomy and clinical significance of the uncinate process and uncovertebral joint: a comprehensive review. Clin Anat 2014;27:431-40.

6. Kohno M, Takahashi H, Ide K, Ishijima B, Yamada K, Nemoto S. A cervical dural arteriovenous fistula in a patient presenting with radiculopathy: case report. J Neurosurg 1996;84:119-23.

7. Horgan MA, Hsu FP, Frank EH. Cervical radiculopathy secondary to a tortuous vertebral artery: case illustration. J Neurosurg 1998;89:489.

8. Henderson CM, Hennessy RG, Shuey HM Jr, Shackelford EG. Posterior-lateral foraminotomy as an exclusive operative technique for cervical radiculopathy: a review of 846 consecutively operated cases. Neurosurgery 1983;13:504-12.

9. Pain in the neck and arm: a multicentre trial of the effects of physiotherapy, arranged by the British Association of Physical Medicine. Br Med J 1966;1:2538.

10. Yoss RE, Corbin KB, Maccarty CS, Love JG. Significance of symptoms and signs in localization of involved root in cervical disk protrusion. Neurology 1957;7:673-83.

11. Honet JC, Ellenberg MR. What you always wanted to know about the history and physical examination of neck pain but were afraid to ask. Phys Med Rehabil Clin N Am 2003;14:473-91.

12. Bussieres AE, Taylor JA, Peterson C. Diagnostic imaging practice guidelines for musculoskeletal complaints in adults: an evidence-based approachpart 3: spinal disorders. J Manipulative Physiol Ther 2008;31:33-88.

13. Wainner RS, Fritz JM, Irrgang JJ, Boninger ML, Del- itto A, Allison S. Reliability and diagnostic accuracy of the clinical examination and patient self-report measures for cervical radiculopathy. Spine (Phila $\mathrm{Pa}$ 1976) 2003;28:52-62.

14. Tong HC, Haig AJ, Yamakawa K. The spurling test and cervical radiculopathy. Spine (Phila $\mathrm{Pa} 1976$ ) 2002;27:156-9.

15. Viikari-Juntura E, Porras M, Laasonen EM. Validity of clinical tests in the diagnosis of root compression in cervical disc disease. Spine (Phila Pa 1976) 1989;14:253-7.

16. Quintner JL. A study of upper limb pain and paraesthesiae following neck injury in motor vehicle accidents: assessment of the brachial plexus tension test of Elvey. Br J Rheumatol 1989;28:528-33.

17. Davidson RI, Dunn EJ, Metzmaker JN. The shoulder abduction test in the diagnosis of radicular pain in cervical extradural compressive monoradiculopathies. Spine (Phila Pa 1976) 1981;6:441-6.

18. Simpson AK, Sabino J, Whang P, Emerson JW, Grauer JN. The assessment of cervical foramina with oblique radiographs: the effect of film angle on foraminal area. J Spinal Disord Tech 2009;22:21-5.

19. Dorwart RH, LaMasters DL. Applications of computed tomographic scanning of the cervical spine. Orthop Clin North Am 1985;16:381-93.

20. Jahnke RW, Hart BL. Cervical stenosis, spondylosis, and herniated disc disease. Radiol Clin North Am 1991;29:777-91.

21. Landman JA, Hoffman JC Jr, Braun IF, Barrow DL. Value of computed tomographic myelography in the recognition of cervical herniated disk. AJNR Am J Neuroradiol 1984;5:391-4.

22. Larsson EM, Holtas S, Cronqvist S, Brandt L. Comparison of myelography, CT myelography and magnetic resonance imaging in cervical spondylosis and disk herniation: pre- and postoperative findings. Acta Radiol 1989;30:233-9.

23. Modic MT, Masaryk TJ, Mulopulos GP, Bundschuh C, Han JS, Bohlman H. Cervical radiculopathy: prospective evaluation with surface coil MR imaging, CT with metrizamide, and metrizamide myelography. Radiology 1986;161:753-9.

24. Malanga GA. The diagnosis and treatment of cervical radiculopathy. Med Sci Sports Exerc 1997;29:S23645.

25. Brown BM, Schwartz RH, Frank E, Blank NK. Pre- 
operative evaluation of cervical radiculopathy and myelopathy by surface-coil MR imaging. AJR Am J Roentgenol 1988;151:1205-12.

26. Park MS, Moon SH, Lee HM, et al. Diagnostic value of oblique magnetic resonance images for evaluating cervical foraminal stenosis. Spine J 2015;15:607-11.

27. Park HJ, Kim SS, Lee SY, et al. A practical MRI grading system for cervical foraminal stenosis based on oblique sagittal images. Br J Radiol 2013;86:20120515.

28. Han JJ, Kraft GH. Electrodiagnosis of neck pain. Phys Med Rehabil Clin N Am 2003;14:549-67.

29. Marinacci AA. A correlation between the operative findings in cervical herniated discs with the electromyograms and opaque myelograms. Electromyography 1966;6:5-23.

30. Leblhuber F, Reisecker F, Boehm-Jurkovic H, Witzmann A, Deisenhammer E. Diagnostic value of different electrophysiologic tests in cervical disk prolapse. Neurology 1988;38:1879-81.

31. Nardin RA, Patel MR, Gudas TF, Rutkove SB, Raynor EM. Electromyography and magnetic resonance imaging in the evaluation of radiculopathy. Muscle Nerve 1999;22:151-5.

32. Negrin P, Lelli S, Fardin P. Contribution of electromyography to the diagnosis, treatment and prognosis of cervical disc disease: a study of 114 patients. Electromyogr Clin Neurophysiol 1991;31:173-9.

33. Partanen J, Partanen K, Oikarinen H, Niemitukia L, Hernesniemi J. Preoperative electroneuromyography and myelography in cervical root compression. Electromyogr Clin Neurophysiol 1991;31:21-6.

34. Dwyer A, Aprill C, Bogduk N. Cervical zygapophyseal joint pain patterns. I: a study in normal volunteers. Spine (Phila Pa 1976) 1990;15:453-7.

35. Mizutamari M, Sei A, Tokiyoshi A, et al. Corresponding scapular pain with the nerve root involved in cervical radiculopathy. J Orthop Surg (Hong Kong) 2010;18:356-60.

36. Persson LC, Carlsson JY. Headache in patients with neck-shoulder-arm pain of cervical radicular origin. Headache 1999;39:218-24.

37. Buszek MC, Szymke TE, Honet JC, et al. Hemidiaphragmatic paralysis: an unusual complication of cervical spondylosis. Arch Phys Med Rehabil 1983;64:601-3.

38. Cloward RB. Diaphragm paralysis from cervical disc lesions. Br J Neurosurg 1988;2:395-9.
39. Stoker GE, Kim HJ, Riew KD. Differentiating c8-t1 radiculopathy from ulnar neuropathy: a survey of 24 spine surgeons. Global Spine J 2014;4:1-6.

40. Misamore GW, Lehman DE. Parsonage-turner syndrome (acute brachial neuritis). J Bone Joint Surg Am 1996;78:1405-8.

41. Cruz-Martinez A, Barrio M, Arpa J. Neuralgic amyotrophy: variable expression in 40 patients. J Peripher Nerv Syst 2002; 7:198-204.

42. Vargo MM, Flood KM. Pancoast tumor presenting as cervical radiculopathy. Arch Phys Med Rehabil 1990;71:606-9.

43. Lees F, Turner JW. Natural history and prognosis of cervical spondylosis. Br Med J 1963;2:1607-10.

44. Bahadir C, Onal B, Yaman V, Yigit S. Relationship between clinical and needle electromyography findings in patients with myotomal muscle weakness caused by cervical disk herniation: a long-term follow-up study. Med J Trakya Univ 2008;25:214-20.

45. Cesaroni A, Nardi PV. Plasma disc decompression for contained cervical disc herniation: a randomized, controlled trial. Eur Spine J 2010;19:477-86.

46. Beckworth WJ, Abramoff BA, Bailey IM, et al. Acute cervical radiculopathy outcomes: soft disc herniations vs osteophytes. Pain Med 2020 Nov 23 [Epub]. https://doi.org/10.1093/pm/pnaa341.

47. Ghasemi M, Masaeli A, Rezvani M, Shaygannejad V, Golabchi K, Norouzi R. Oral prednisolone in the treatment of cervical radiculopathy: a randomized placebo controlled trial. J Res Med Sci 2013;18:S43-6.

48. Kuijper B, Tans JT, Beelen A, Nollet F, de Visser M. Cervical collar or physiotherapy versus wait and see policy for recent onset cervical radiculopathy: randomised trial. BMJ 2009;339:b3883.

49. Cleland JA, Fritz JM, Whitman JM, Heath R. Predictors of short-term outcome in people with a clinical diagnosis of cervical radiculopathy. Phys Ther 2007;87:1619-32.

50. Persson LC, Carlsson CA, Carlsson JY. Long-lasting cervical radicular pain managed with surgery, physiotherapy, or a cervical collar: a prospective, randomized study. Spine (Phila Pa 1976) 1997;22:751-8.

51. Diwan S, Manchikanti L, Benyamin RM, et al. Effectiveness of cervical epidural injections in the management of chronic neck and upper extremity pain. Pain Physician 2012;15:E405-34.

52. Parivash SN, Kranz PG, Gray L, Amrhein TJ. CT 
fluoroscopy-guided interlaminar epidural steroid injections in the cervical spine: rate of nontarget injection into the retrodural space of okada. AJR Am J Roentgenol 2018;211:426-31.

53. Amrhein TJ, Parivash SN, Gray L, Kranz PG. Incidence of inadvertent dural puncture during CT fluoroscopy-guided interlaminar epidural corticosteroid injections in the cervical spine: an analysis of 974 cases. AJR Am J Roentgenol 2017;209:656-61.

54. Maduri R, Cossu G, Aureli V, Wuthrich SP, Bobinski L, Duff JM. Transtubular anterior cervical foraminotomy for the treatment of compressive cervical radiculopathy: surgical results and complications in a consecutive series of cases. Asian Spine J 2020 Nov 16 [Epub]. https://doi.org/10.31616/asj.2020.0323.

55. Gadia A, Shah K, Nene A. Cervical kyphosis. Asian Spine J 2019;13:163-72.

56. Hilibrand AS, Robbins M. Adjacent segment degeneration and adjacent segment disease: the consequences of spinal fusion? Spine J 2004;4:190S-4S.

57. Hilibrand AS, Carlson GD, Palumbo MA, Jones PK, Bohlman HH. Radiculopathy and myelopathy at segments adjacent to the site of a previous anterior cervical arthrodesis. J Bone Joint Surg Am 1999;81:51928.

58. Cao F, Liu T, Xu Y, Han H, Dong R, Feng S. Comparison of clinical and radiographic changes after Bryan disc arthroplasty versus ACDF: a 60-month followup on 120 patients. World J Neurosci 2015;5:40-8.

59. Zhang X, Zhang X, Chen C, et al. Randomized, controlled, multicenter, clinical trial comparing BRYAN cervical disc arthroplasty with anterior cervical decompression and fusion in China. Spine (Phila $\mathrm{Pa}$ 1976) 2012;37:433-8.

60. Gornet M. Cervical disc arthroplasty: an update on current practices. Int J Spine Surg 2020;14:S2-4.

61. Wang QL, Tu ZM, Hu P, et al. Long-term results comparing cervical disc arthroplasty to anterior cervical discectomy and fusion: a systematic review and meta-analysis of randomized controlled trials. Orthop Surg 2020;12:16-30.
62. Zou S, Gao J, Xu B, Lu X, Han Y, Meng H. Anterior cervical discectomy and fusion (ACDF) versus cervical disc arthroplasty (CDA) for two contiguous levels cervical disc degenerative disease: a metaanalysis of randomized controlled trials. Eur Spine J 2017;26:985-97.

63. Park CK, Ryu KS. Are controversial issues in cervical total disc replacement resolved or unresolved?: a review of literature and recent updates. Asian Spine J 2018;12:178-92.

64. Mansfield HE, Canar WJ, Gerard CS, O’Toole JE. Single-level anterior cervical discectomy and fusion versus minimally invasive posterior cervical foraminotomy for patients with cervical radiculopathy: a cost analysis. Neurosurg Focus 2014;37:E9.

65. Won S, Kim CH, Chung CK, et al. Comparison of cervical sagittal alignment and kinematics after posterior full-endoscopic cervical foraminotomy and discectomy according to preoperative cervical alignment. Pain Physician 2017;20:77-87.

66. Church EW, Halpern CH, Faught RW, et al. Cervical laminoforaminotomy for radiculopathy: symptomatic and functional outcomes in a large cohort with long-term follow-up. Surg Neurol Int 2014;5:S53643.

67. Bydon M, Mathios D, Macki M, et al. Long-term patient outcomes after posterior cervical foraminotomy: an analysis of 151 cases. J Neurosurg Spine 2014;21:727-31.

68. Faught RW, Church EW, Halpern CH, et al. Longterm quality of life after posterior cervical foraminotomy for radiculopathy. Clin Neurol Neurosurg 2016;142:22-5.

69. Caglar YS, Bozkurt M, Kahilogullari G, et al. Keyhole approach for posterior cervical discectomy: experience on 84 patients. Minim Invasive Neurosurg 2007;50:7-11.

70. Jagannathan J, Sherman JH, Szabo T, Shaffrey CI, Jane JA. The posterior cervical foraminotomy in the treatment of cervical disc/osteophyte disease: a single-surgeon experience with a minimum of 5 years' clinical and radiographic follow-up. J Neurosurg Spine 2009;10:347-56. 